\title{
Manual extraction of the rectosigmoid foreign body
}

\author{
Hao-Yun Hung ${ }^{1}$ and Cheng-Maw $\mathrm{Ho}^{2 *}$ \\ ${ }^{1}$ Department of Surgery, New Taipei Hospital, New Taipei City, Taiwan \\ ${ }^{2}$ Department of Surgery, National Taiwan University Hospital, Taipei, Taiwan
}

\section{Introduction}

Retained foreign bodies clearly documented at or above the rectosigmoid colon were rare. Kurer MA et al. [1] had reviewed 193 patients with retained colorectal foreign bodies and $97.4 \%$ were male. Various rectal foreign bodies have been reported in the literature, among which bottles and sexual toys were most commonly encountered [1]. Some characteristics of foreign bodies such as smooth surface, a blunt caudal end, or friable nature, make them difficult for safely manual retrieval and require laparotomy and colostomy. It is technically more demanding for those deeply migrated at rectosigmoid region. We describes a patient who presented with impacted rectosigmoid foreign body which was retrieved successfully manually without endoscopic or laparotomy procedures.

\section{Case description}

A 39-year-old otherwise healthy man presented to the emergency department with abdominal pain and fullness. He stated that a dildovibrator was inserted into his rectum and not able to take it out.

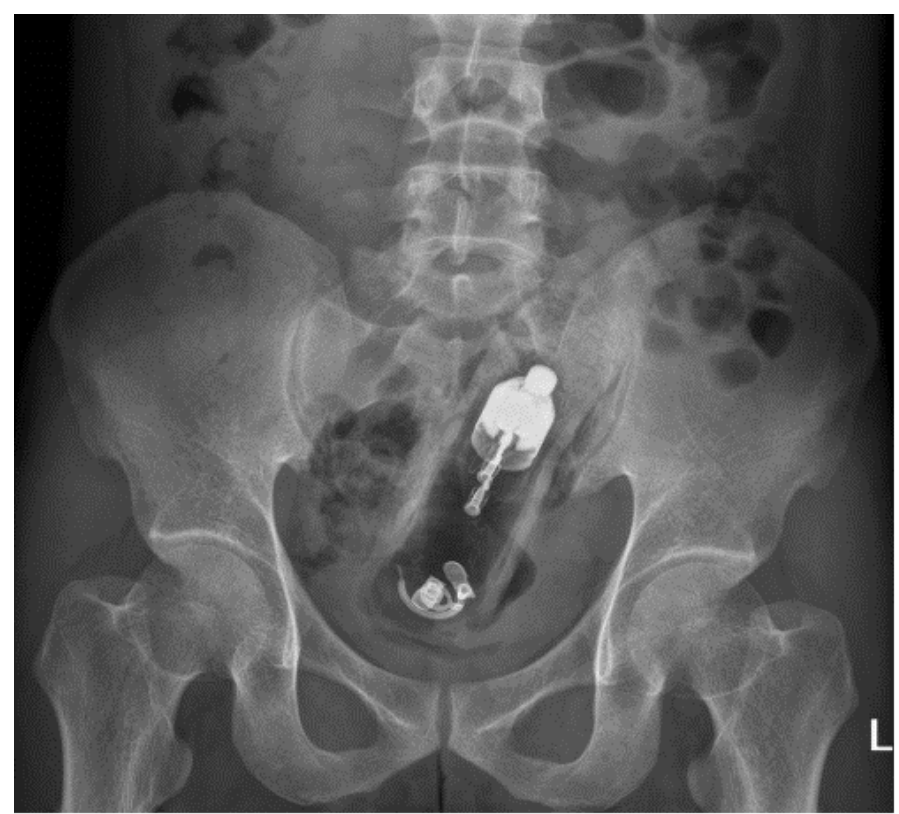

Figure 1. Plain X-ray of the abdomen reveals an impacted foreign body in the rectosigmoid region.

Copyright: (C)2015 Hung HY. This is an open-access article distributed under the terms of the Creative Commons Attribution License, which permits unrestricted use, distribution, and reproduction in any medium, provided the original author and source are credited.
Physical examination revealed a palpable mass at left lower abdomen without peritoneal signs. The tip of the foreign body was barely reachable manually on rectal examination. The plain-film radiography of his pubic area showed a column-shaped object impacted within the rectosigmoid colon (Figure 1). Under conscious sedation, anal dilatation was done and the object was manipulated into the rectum by abdominal massage. As the assistant's hands applied steady abdominal pressure milking the object downward and the surgeon grasped the tail of the foreign body with fingers, the $17 \mathrm{~cm}$ long rubber-covered dildovibrator was delivered out transanally, along with some blood tinged mucus discharge. He was further observed for the appearance of any peritoneal signs. He regained bowel activity and resumed oral intake within 24 hours. His recovery was uneventful. He was later diagnosed with Human Immunodeficiency Virus (HIV) infection and received anti-HIV therapies.

\section{Discussion}

Colorectal foreign bodies may cause intestinal obstruction, perforation, rectal fistula, perianal abscesses, anal stenosis or incontinence [1]. Lubricant use might reduce the risk of perforation when attempts to extract the foreign body manually and to apply abdominal wall pressure. It, however, also reduces the friction between fingers and the foreign body and makes firmly manual grasping exhausting. Endoscopic approach using a pneumatic dilatation balloon normally used in achalasia patients might be of help [2]. Laparotomy is usually reserved for failed nonoperative managements or bowel perforation [2]. Endoscopic approach using a pneumatic dilatation balloon normally used in achalasia patients might be of help. As these injuries due mostly to social behaviors, HIV and other infection screenings should be actively discussed with these patients. Physicians at work should be alert of this and provide adequate self-protection.

In conclusion, manual delivery of the impacted rectosigmoid foreign body is safe and feasible.

\section{References}

1. Kurer MA, Davey C, Khan S, Chintapatla S (2010) Colorectal foreign bodies: a systematic review. Colorectal Dis 12: 851-861. [Crossref]

2. Jan J Koornstra, Rinse K Weersma (2008) Management of rectal foreign bodies: Description of a new technique and clinical practice guidelines. World $J$ Gastroenterol14: 4403-4406. [Crossref]

Correspondence to: Cheng-Maw Ho, Department of Surgery, National Taiwan University Hospital 7, Chung-Shan South Rd, Taipei 100, Taiwan, Tel: +886-223123456-65914, Fax: +886-2-23568810; E-mail: miningho@ntu.edu.tw

Received: June 26, 2015; Accepted: August 11, 2015; Published: August 14, 2015 